\title{
Comportamiento no verbal: más allá de la comunicación y el lenguaje [Reseña]
}

\author{
Rafael M. López Pérez, Fernando Gordillo León y Marta Grau Olivares (Coords.) \\ Pirámide, Madrid, 2016
}

Laura Ortiz Zapata ${ }^{1}$

(1) Mushin Personas e Influencia

El comportamiento no verbal es uno de los temas más controvertidos, hasta enigmáticos, con los que trabajan los profesionales de las ciencias del comportamiento. Todos hemos tenido ocasión de escuchar afirmaciones del tipo: si cruza las piernas, se está protegiendo; si mira arriba a la derecha, miente. ¿Qué hay de verdad en estas afirmaciones? Este manual sale a la luz con ánimo de clarificar estas cuestiones, y otras de mucho mayor calado, así como ofrecer un análisis completo, riguroso e integral de los conocimientos imprescindibles para todo analista del comportamiento no verbal. Quizás por ello, antes de cualquier otra manifestación, los autores advierten que el enfoque del análisis de las conductas no verbales debe ser responsable. Responsable en cuanto la respuesta a la frecuente pregunta: ¿qué significa esta conducta no verbal? debe ser siempre "depende"; ya que, sin contemplar los diferentes factores de análisis en conjunto, es improcedente hacer cualquier tipo de inferencia. Es decir, toda interpretación de una conducta no verbal debe ser valorada en su contexto. En ocasiones, el contexto puede estar anclado en una serie de señales codificadas y compartidas. En otras, activa una serie de respuestas independientes de un sistema codificado (lenguaje) o codificado y compartido (comunicación). De ahí, la elección del concepto "comportamiento no verbal" como título de la obra y de su subtítulo "más allá de la comunicación y el lenguaje".

La obra recoge las aportaciones de un nutrido grupo de autores, quienes compilan los resultados de investigación y aplicaciones más recientes, y oportunas, para ofrecer un documento con vocación de ser referente en el conocimiento del comportamiento no verbal para los países de habla hispana. Es el resultado de años de investigación y revisión del equipo de profesores, investigadores y profesionales vinculados a la Fundación Universitaria Behavior \& Law y, concretamente, a sus programas de formación en esta área. Este hecho determina la estructura de contenidos del manual y sugiere dos maneras diferentes de utilizarlo. En primer lugar, como un manual de estudio para quienes deseen formarse en el análisis del comportamiento no verbal: desde el conocimiento elemental, los procesos psicológicos básicos del comportamiento, hasta el desarrollo de las competencias del analista en diversos contextos. En segundo lugar, como un manual de consulta para quienes estén interesados en profundizar en los procesos emocionales asociados al comportamiento no verbal, los diferentes canales expresivos o los protocolos de análisis.

El manual se estructura en cinco grandes bloques temáticos, más el consabido apartado dedicado a la referencias de las fuentes documentales que avalan los contenidos. A este último los autores atribuyen gran importancia considerando la cantidad de fuentes manejadas, alrededor de 800 .

El primer bloque, en un único capítulo, es la carta de presentación de los procesos psicológicos que explican y predicen las conductas observadas en los seres humanos. La taxonomía de Kuhl (1986) es la opción elegida por los autores: procesos emocionales, motivacionales y cognitivos. ¿Qué particularidades describen cada uno de ellos? En función de estos subsistemas de la mente humana ¿Cómo se relacionan las personas con el mundo? ¿Cómo interactúan y se relacionan estos procesos entre sí? Son cuestiones que obtienen respuesta en este capítulo. Los procesos emocionales reciben una atención especial, con epígrafes destinados a revelar la función social y comunicativa de la emoción mediante la puesta en escena de la expresión y el reconocimiento emocional.

El segundo bloque despliega, en cinco capítulos, el conocimiento que todo analista del comportamiento no verbal debe dominar sobre 8 canales expresivos: expresión facial, expresión corporal, prosémica, prosodia emocional, háptica, apariencia, oculésica y 
Ortiz, L. (2016). [Reseña del libro Comportamiento no verbal: más allá de la comunicación y el lenguaje]. Madrid: Pirámide.

Behavior \& Law Journal, 2 (1). 59-61.

cronémica. Los cuatro primeros se desarrollan en capítulos separados, los cuatro últimos se agrupan en un capítulo denominado: otros canales. La expresión facial es el primer canal a explorar y lo es por un criterio consensuado y aceptado: el reconocimiento de la expresión emocional, a través de la decodificación de la expresión facial, resulta decisivo en las relaciones interpersonales. Tras un análisis minucioso de los resultados de investigación en expresión facial de las emociones, se exponen diferentes sistemas de codificación: FAST, FACS, EMPFACS, FACSAID, MAX, FACES, FACE; para continuar con la exposición de dos temas de máxima actualidad. Uno de ellos, reciente, las microexpresiones. El otro, un clásico, la detección de la mentira. La exposición de los canales expresivos continúa con uno de los temas que más debate ha provocado en la comunidad científica y en la vida cotidiana, la expresión corporal. Como advierten los autores, la tarea de investigación en este ámbito ha sido escasa pero la tarea de interpretación y divulgación ha sido importante. Quizás por ello, este capítulo resulta especialmente interesante $y$, sobremanera, la premisa de interpretar de forma combinada la información obtenida en los diferentes componentes de la expresión corporal: movimiento, postura, orientación corporales, gestos... Estos componentes son diseccionados en el texto junto a alguna propuesta para su codificación. Un neologismo acuñado en la tradición antropológica, la proxémica, designa las relaciones de proximidad y alejamiento entre las personas y los objetos durante la interacción, las posturas adoptadas y la existencia o ausencia de contacto físico. En cuanto pueden ser un indicador de la distancia emocional (modulada, eso si, por los parámetros culturales) constituye el tercero de los canales expresivos a considerar en el análisis del comportamiento no verbal. De ello da cuenta el siguiente capítulo. Del habla a la prosodia y de la prosodia a la prosodia emocional, para concluir con la descripción de los recursos científicos para evaluar el reconocimiento de la prosodia emocional constituyen los contenidos del capítulo sucesivo. El análisis de la prosodia emocional solo ha sido posible en los últimos años gracias al desarrollo de ciertas tecnologías que lo facilitan. Por ello, nos encontramos ante un capítulo que merece especial atención para quienes deseen actualizar sus conocimientos en este ámbito. El último capítulo de este bloque lo integran los restantes canales expresivos. Aunque, tradicionalmente, se han tratado de forma accesoria a los anteriores, los autores consideran necesario su análisis. Ahora bien, mencionan cómo el escaso desarrollo de un conocimiento con suficientes avales científicos, no ha permitido una exposición tan pormenorizada como la de expresión facial o corporal. En primer lugar, se presenta el canal háptico o expresión de los mecanismos sensoriales relacionados con el contacto físico que permiten obtener información sobre ciertas características de los objetos (dureza, tamaño, volumen, peso, textura...) o de los sujetos y las interacciones entre ellos (contacto, intimidad...). A continuación, se expone la importancia de la apariencia, o imagen personal, en aspectos relevantes en las relaciones humanas como la formación de impresiones. La oculésica atiende a la conducta visual, es decir, la mirada. Es el siguiente canal expresivo descrito en el manual, con una mención especial a la relación entre mirada y detección de la mentira. Por último, se propone la observación de cómo las personas utilizamos el tiempo y cómo lo hacemos en relación con otras personas. Esta información, se conoce como cronémica.

El tercer bloque profundiza en la relación comportamiento y personalidad. Tras una exposición de diferentes modelos que interpretan la personalidad, los autores optan por desplegar con amplitud diversos modelos bajo el marco teórico que rige su propuesta: el de rasgos. El criterio principal que siguen los autores para esta decisión es fácil de comprender y guarda una estrecha relación con el pragmatismo inherente al analista, en este caso, al analista de comportamiento no verbal. La teoría de los rasgos permite inferir características de la personalidad de un sujeto a partir de una serie de indicadores, entre ellos, aquellos descritos en el comportamiento no verbal. Luego, el análisis del comportamiento no verbal puede ser una herramienta útil para describir la personalidad. Además, permite extraer información sobre los rasgos de personalidad con la mera observación de la conducta de la persona analizada y sin necesidad de que ésta participe. En definitiva, es útil para el perfilado indirecto de personalidad. Obviamente, si interesa conocer la personalidad de alguien es para inferir su conducta futura o pasada, esta última de forma particular en el terreno de la investigación policial. Cómo y cuándo realizar este perfilado indirecto son cuestiones objeto de análisis en el manual.

El cuarto bloque está dedicado a la presentación de dos protocolos de análisis del comportamiento no verbal: el protocolo FEAP (Facial Expression Analysis Protocol) y el protocolo NBAM (Nonverbal Behavior Analysis Matrix). En un primer capítulo se abordan los 
supuestos teóricos, se exponen de forma minuciosa las unidades de análisis y se presenta el procedimiento secuencial, en cuatro fases, del protocolo de análisis de la expresión facial (FEAP). El protocolo se sustenta en tres afirmaciones empíricamente contrastadas: a) la universalidad de la expresión facial de la emociones; b) la existencia de vías neuronales diferentes, por un lado para los movimientos faciales intencionados, por otro para los automáticos y c) los núcleos temáticos cognitivos asociados a las emociones. Es decir, se asume que ante ciertas interpretaciones cognitivas, se suscitarán ciertas emociones. A continuación, se exponen los contenidos relativos al NBAM y, en un tercer capítulo de este bloque capítulo se ejemplifica, con un estudio de caso, la aplicación de la matriz de análisis del comportamiento no verbal (NBAM). El NBAM se basa en el estudio de tres elementos: el proceso emocional, el patrón individual y los canales expresivos. Para facilitar el análisis, el protocolo pone a disposición una serie de tablas (matrices) que ayudan a recoger la información de forma sistemática y ordenada. Cada matriz se aplica en uno de los cinco niveles (del 0 al 4) y está adaptada al logro del objetivo de cada nivel: 0 . Línea basal, patrón base de comportamiento; 1 . Datos, análisis de datos conductuales observables; 2 . Inferencias, establecimiento de inferencias basadas en los datos observables; 3. Hipótesis, establecimiento de hipótesis de trabajo y 4. Propuesta de intervención, sugerencias operativas en función del ámbito profesional de la intervención.

El quinto, y último bloque, se destina a las aplicaciones del análisis del comportamiento no verbal en diversos ámbitos profesionales. Siete capítulos que abordan intervenciones en educación, política, investigación policial, mediación, medicina asistencial, medicina pericial y videovigilancia. Se trata de capítulos breves, dos-cuatro páginas que nos sugieren diversas formas de aprovechar los conocimientos adquiridos en el desarrollo de la actividad profesional.

En resumen, nos encontramos ante la primera edición de un manual que ha requerido un gran esfuerzo de producción, de análisis y síntesis del conocimiento científicamente elaborado para el análisis del comportamiento no verbal. Con dos propuestas o protocolos de análisis y una variedad de experiencias de uso en diversos ámbitos laborales. Sin lugar a dudas, esta primera edición solo es el inicio de un esfuerzo de futuro por continuar ofreciendo a la comunidad científica y a los profesionales del campo los avances que en esta materia de desarrollen en un futuro. 